\title{
Towards a better understanding of the latest warm climate: The PMIP Last Interglacial Working Group
}

\author{
Bette L. Otto-Bliesner', P. Scussolini², E. Capron³, M. Kageyama ${ }^{4}$ and A. Zhao ${ }^{5}$
}

\begin{abstract}
The Last Interglacial is one of the five priorities within the CMIP6-PMIP4 initiative. Its $127 \mathrm{kyr}$ BP model experiment allows for an assessment of climate model fidelity during a period of Northern Hemisphere warmth, sea-level high stand, and regional hydroclimate changes.
\end{abstract}

The main changes in forcing during the Last Interglacial (LIG) as compared to present are in the latitudinal and seasonal distribution of incoming solar radiation. Differences in the orbital configuration between the LIG and modern resulted in pronounced insolation anomalies at the Northern Hemisphere (NH) summer solstice; these anomalies are latitudinally similar but much larger than those during the Holocene (Fig. 1)

Proxy records document that these insolation anomalies altered regional hydroclimates, e.g. by enhancing the summer monsoon precipitation over North Africa and southeast Asia during the Holocene (COHMAP 1988) and during interglacials of the last 224 kyr (Wang et al. 2008). Pollen and macro-fossil evidence indicate that in the mid-Holocene, the boreal forest extended farther north than today (Prentice et al. 2000) and during the LIG (CAPE-Last interglacial project members 2006) it extended to the Arctic coast, except in Alaska and central Canada. Ice cores and proximal marine records indicate that the Greenland ice sheet survived the warmer temperatures of the LIG, though with significantly reduced extent and volume (Sime et al. 2013).
140
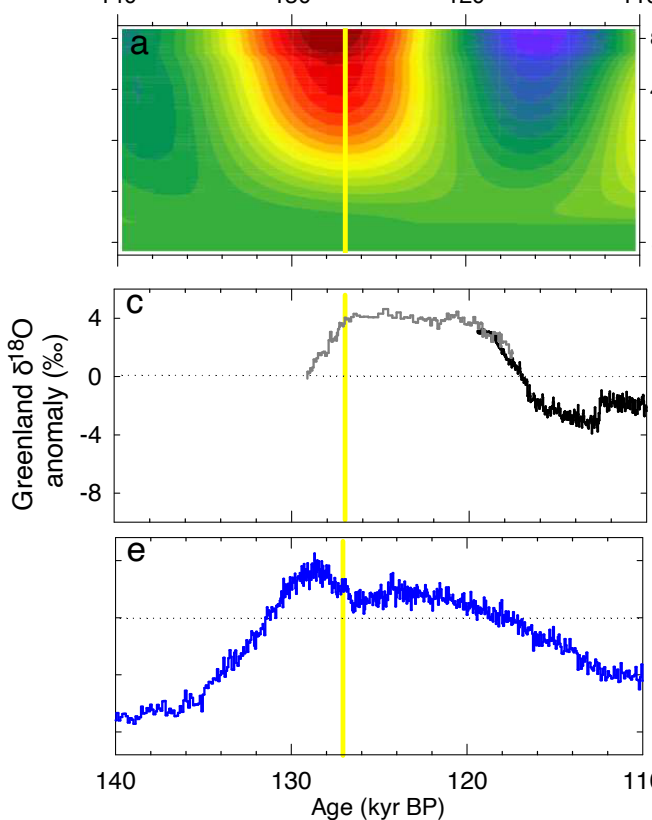

CMIP, PMIP, and IPCC

Studying the Holocene, our current interglacial, has been a cornerstone of the Paleoclimate Modelling Intercomparison Project (PMIP) since the early 1990s (see Joussaume and Taylor, this issue; Braconnot et al. this issue), and has contributed to the evaluation of climate models starting with the Intergovernmental Panel on Climate Change (IPCC) Second Assessment Report in 1995 (see Kageyama et al. this issue, p. 68). Although the LIG had been on the radar of the IPCC since the first assessment report, it gained increasing attention in the fourth and fifth assessments (AR4 and AR5) due to its relevance for future projections of Earth system responses in a warm climate state. Indeed, the LIG was elevated to the AR4 Summary for Policymakers, which included these statements: "There is very high confidence that maximum global mean sea level during the last interglacial period $(129,000$ to 116,000 years ago) was, for several thousand years, at least $5 \mathrm{~m}$ higher than present, and high confidence that it did not exceed $10 \mathrm{~m}$ above present." Furthermore, "this change in sea level occurred in the context of different orbital forcing and with high-latitude surface temperature, averaged over several
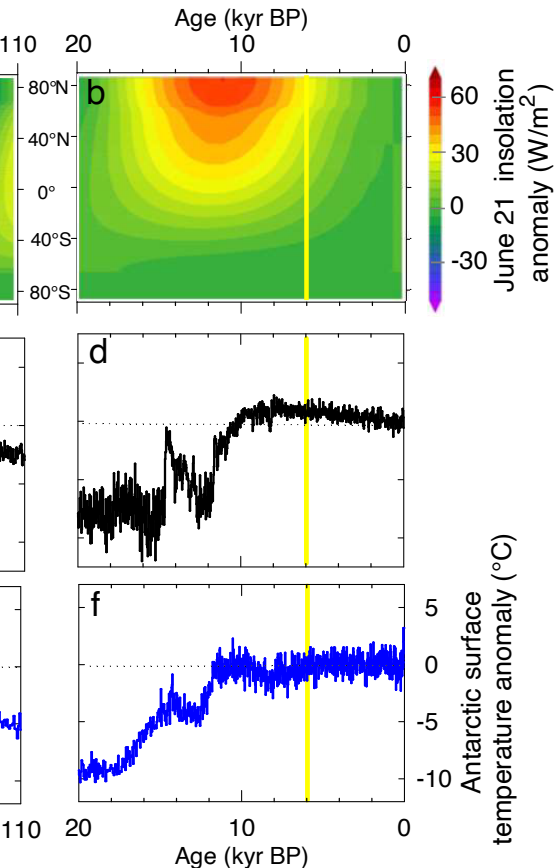

Figure 1: Insolation (Berger 1978) forcing and climate records of Antarctic surface temperature and Greenland $\delta^{18} \mathrm{O}$ for the Last Interglacial (left) and Holocene (right). Anomalies are relative to their average value of the last 1000 years. Yellow lines indicate the periods selected for the lig127k and midHolocene simulations with the PMIP climate models. Figure modified from Otto-Bliesner et al. (2017). thousand years, at least $2^{\circ} \mathrm{C}$ warmer than present (high confidence)."

The first multi-model ensemble for the LIG, as assessed in the AR5, compiled a set of 23 time-slice climate model simulations of the early LIG (130 to 125 kyr before present (BP)) by 14 models, encompassing a range of model complexities and various choices in the forcings (Lunt et al. 2013). However, the models in general underestimated the magnitude of the reconstructed temperature responses. It was, moreover, difficult to use these results to assess model reliability for simulating feedbacks for a warm climate state, as the models in this set of simulations for the LIG were mostly older and/ or lower-resolution versions of the models used for the future projections in the Climate Modelling Intercomparison Project (CMIP) Phase 5 and in IPCC's AR5.

To provide more solid results, and to improve comparability with other simulations, such as of future climate, a coordinated LIG experiment was proposed as a CMIP6-PMIP4 simulation, setting a common experimental protocol for modeling groups to run with the same model and same resolution as the CMIP6 DECK (Diagnostic, Evaluation and Characterization of Klima) simulations (Eyring et al. 2016; Otto-Bliesner et al. 2017). At the "Warm extremes" workshop of the PAGES QUIGS working group in Cambridge in 2015 (pastglobalchanges. org/calendar/26910), the proxy and modeling communities identified the 127 kyr BP time slice as target for the CMIP6-PMIP4 LIG experiment. This concerted effort within both the model and data communities also led to a specific parallel effort to: (1) compile and build appropriate data time slices using ice-core and marine data and (2) provide guidance and recommendation on the use of existing data compilations to evaluate model runs (Capron et al. 2017).

Highlights of results from the CMIP6PMIP4 lig127k experiment

Seventeen CMIP6-PMIP4 climate models completed the priority LIG experiment, called lig127k (see Otto-Bliesner et al. 2021 and Kageyama et al. 2021 for further details).

In response to the large boreal summer insolation anomalies with respect to the modern period, the $\mathrm{NH}$ high latitudes experience strong warming in June-July-August (JJA) 
(a) $40^{\circ}-90^{\circ} \mathrm{N} \mathrm{JJA}$

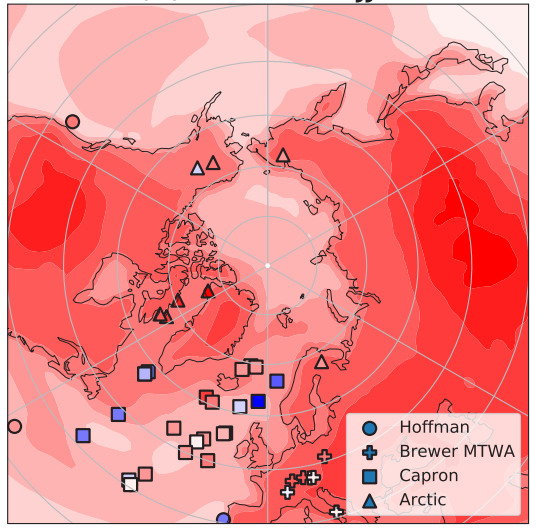

(b) $40^{\circ}-90^{\circ} \mathrm{N} \mathrm{DJF}$

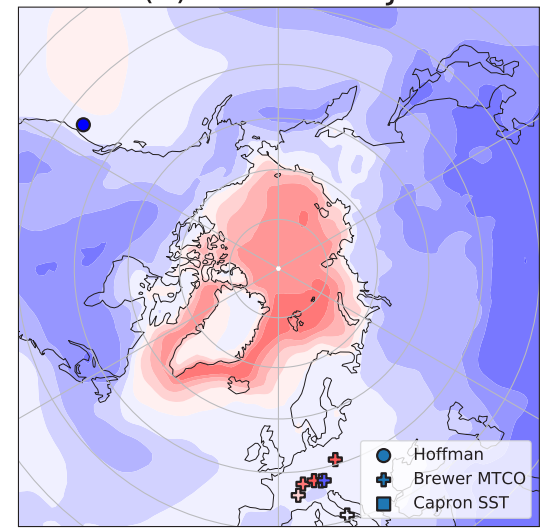

(c) $40^{\circ}-90^{\circ} \mathrm{N}$ Annual

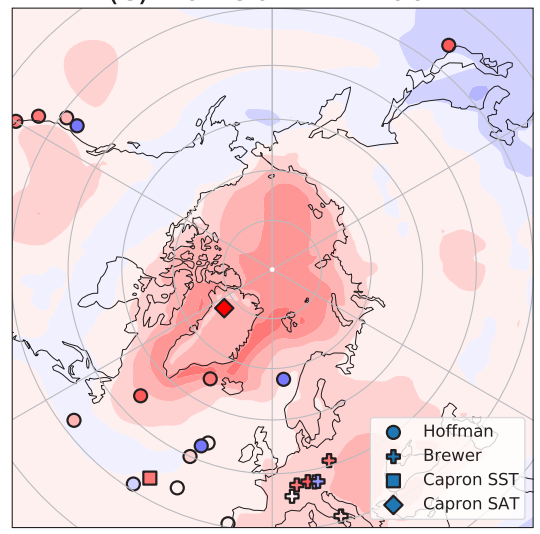

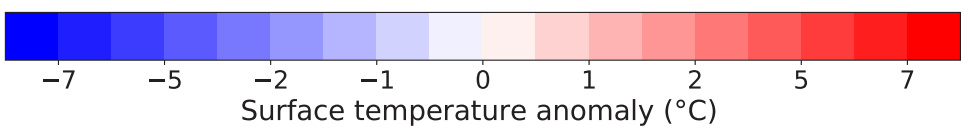

Surface temperature anomaly $\left({ }^{\circ} \mathrm{C}\right)$

Figure 2: Comparison of results of the CMIP6-PMIP4 lig127k simulations and proxy records. Arctic $\left(40^{\circ}-90^{\circ} \mathrm{N}\right)$ surface temperature anomaly between $127 \mathrm{kyr} B \mathrm{BP}$ to the preindustrial period from models (ensemble average in colors) and proxies (filled markers), doi.org/10.5194/cp-17-63-2021-supplement): (A) June-July-August (JJA), (B) December-January-February (DJF), (C) annual. The preindustrial reference is 1850 CE for model anomalies and for the data is 1870-1899. Figure modified from OttoBliesner et al. (2021).

relative to the pre-industrial (PI) simulations, with greater warming over the continents than the oceans (Fig. 2). This warming agrees well with reconstructions of summer temperatures except in the northwestern North Atlantic and Nordic seas, where marine reconstructions suggest significant cooling. One potential reason for this mismatch is that the highly uncertain meltwater flux from remnant ice sheets over Canada and Scandinavia is not included in the experiment protocol. Positive feedbacks with the cryosphere and ocean provide a "climate memory" effect that entails simulated high latitude summer warming to extend virtually year-round. The multi-model mean annual minimum sea ice extent in the Arctic is reduced by $50 \%$ relative to the $\mathrm{PI}$ simulations.

Precipitation simulated for the LIG exceeds that for the Pl over most boreal land areas, agreeing with a significant majority of the available proxies (Scussolini et al. 2019). In particular, summer monsoonal precipitation and areal extent are enhanced over northern Africa, Arabian Peninsula, India, southeast Asia, northwestern Mexico, and the southwestern US. The opposite happens for the South American, South African, and Australian monsoons. The LIG monsoon changes are mostly of the same sign but of greater magnitude than those in the CMIP6-PMIP4 mid-Holocene simulations. Simulations of the LIG hydrology indicate potentially large changes in river discharge for several $\mathrm{NH}$ basins, possibly with the development of a much wider river network over North Africa (Scussolini et al. 2020).

\section{Perspectives}

Looking forward, much more could be done to understand the LIG.

Additional snapshots of the LIG and transient simulations would allow analyses of the temporal complexity of the LIG. Existing LIG compilations of temperature (e.g. Capron et al. 2017; Hoffman et al. 2017) should be extended to cover data-scarce areas of the globe, i.e. the Southern Hemisphere and e.g. the Indian and Pacific Oceans. Available terrestrial records often reflect the so-called LIG temperature optimum, which was not globally synchronous, and can hardly be associated with specific time slices during the LIG. Transient simulations would enable an integrated approach for addressing the model-to-proxy mismatch potentially due to chronological inaccuracy and bias of proxy records, and allow application of data assimilation methods. Continued development of sea-ice and hydroclimate reconstructions would provide additional metrics for comparison to model simulations.

Modeling the transition into the LIG from Termination 2 is required to understand how changes in climate and ice sheets during the preceding penultimate deglaciation (see Ivanovic et al. this issue) influenced the early LIG, e.g. the overshoot in Antarctic surface temperatures and atmospheric carbon dioxide, as well as possibly the collapse of the West Antarctic ice sheet early in the LIG. Modeling the late part of the LIG will be an important test of the ability of models to simulate the glacial inception. Other opportunities include using data and fully coupled climate-ice sheet models for simulating the transition into, during, and out of the LIG, to evaluate the feedbacks among the atmosphere, ocean, sea ice, biosphere, and ice sheets. In addition, coordination of an integrated model-data project of the earlier Marine Isotope Stage 11 interglacial would allow evaluation of the sensitivity of the Greenland ice sheet to warmth, which was more muted but lasted longer than at the LIG.

The CMIP6-PMIP4 lig127k results illustrate the potential of the LIG to inform future projections. More than half of the models simulate a LIG retreat of the AugustSeptember Arctic sea-ice edge, similar to the average August-September Arctic sea-ice edge of the last two decades. Additionally, the models that show a strong reduction in the Arctic minimum sea-ice area to LIG forcing also show it in the CMIP6 1 pctCO2 coordinated experiment. Further, for several regions of the $\mathrm{NH}$, observed and projected changes in atmospheric circulation and rain patterns, in turn linked to the ongoing trend in Arctic amplification of warming and the response of the polar jet stream, may have had counterparts in the LIG climate. Finally, further integrated model-data investigations are required to firmly elucidate whether the West Antarctic ice sheet was a major contributor to the large LIG global sea level and inform on its potential collapse in the future.

\section{AFFILIATIONS}

${ }^{1}$ Climate and Global Dynamics Laboratory, National Center for Atmospheric Research, Boulder, CO, USA ${ }^{2}$ Institute for Environmental Studies, Vrije Universiteit Amsterdam, Netherlands

${ }^{3}$ Institut des Géosciences de l'Environnement, CNRS, Grenoble, France

${ }^{4}$ Laboratoire des Sciences du Climat et de

I'Environnement/Institut Pierre-Simon Laplace, Gif-sur-Yvette, France

${ }^{5}$ Department of Geography, University College London, UK

\section{CONTACT}

Bette Otto-Bliesner: ottobli@ucar.edu

\section{REFERENCES}

Berger A (1978) J Atmos Sci 35: 2362-2367

CAPE-Last Interglacial project members (2006) Quat Sci

$$
\text { Rev 25: 1383-1400 }
$$

Capron E et al. (2017) Quat Sci Rev 168: 137-150

COHMAP Members (1988) Science 241: 1043-1042

Eyring V et al. (2016) Geosci Model Dev 9: 1937-1958 Hoffman JS et al. (2017) Science 355: 276-279 Kageyama M et al. (2021) Clim Past 17: 37-62 Lunt DJ et al. (2013) Clim Past 9: 699-717

Otto-Bliesner BL et al. (2017) Geosci Model Dev 10: 3979-4003

Otto-Bliesner BL et al. (2021) Clim Past 17: 63-94

Prentice IC et al. (2000) J Biogeogr 27: 507-519

Scussolini P et al. (2019) Sci Adv 5: eaax7047

Scussolini P et al. (2020) Geophys Res Lett 47: e2020GL089375

Sime LC et al. (2013) Quat Sci Rev 67: 59-80

Wang Y et al. (2008) Nature 451: 1090-1093 